\title{
Balance in elderly: overview and personal experience in Paroxysmal Positional Vertigo (PPV)
}

\author{
G Chiarella*, E Cassandro \\ From de Senectute: Age and Health Forum \\ Catanzaro, Italy. 5-7 December 2009
}

\section{Background}

Vestibular impairment is an underlying cause in about $45 \%$ of elderly dizziness complaining.

Balance results from a complex integration of inputs at central nervous system level (vestibular, visual and somesthetic). Disorders of balance in elderly show an increase in terms of prevalence and severity and can result from impairment in sensory, motor and central processing systems for a specific pathology or for physiological progressive loss of function.

All the balance subsystems [1] are involved, with a reduction in:

Vestibular receptor cells (20\% to $40 \%$ ) [2]

Visual acuity, field and depth, contrast sensitivity

Myelinated and unmyelinated fibers (axonal atrophy with decline in conduction velocity and sensory discrimination)

Speed transmission and processing in brain

Muscle and joint strenght and quality

Vestibular problems are very frequent in elderly starting from a labirintine ipofunction, we focus on PPV, the most frequent peripheral vestibular disease, a condition leading to high risk of fall at this age, to evaluate its real weight in elderly, from an epidemiological point of view.

\section{Materials and methods}

912 PPV patients (mean 55.2yrs) (2005-2008). Complete otoneurologic evaluation (caloric stimulation, PPV identification through Dix-Hallpike [3] and Pagnini-McClure [4] manoeuvres and anamnestic questionnaire for risk factors.

\section{Results}

Females more affected, (1.7/1). Incidence higher between $5^{\text {th }}$ and $6^{\text {th }}$ decade $(57.9 \%)$, and decrease between the 7 th and 8 th, particularly in females.

This appears to be in contrast with hypothesis that macular degeneration could enhance the formation of otolithic clusters in labyrinth.

\section{Conclusion}

Frequency, simple diagnosis and high effective treatment in PPV have led to more widespread use of vestibular rehabilitation procedures. Because of the high incidence in $6^{\text {th }}$ decade of life we strongly suggest to take in the right consideration the risk of fall linked to this condition.

\section{Published: 19 May 2010}

\section{References}

1. Sturnieks DL, St George R, Lord SR: Balance disorders in the elderly. Neurophysiol Clin. 2008, 38(6):467-478.

2. Alpini D, Cesarani A, Fraschini F, et al: Aging and vestibular system: specific tests and role of melatonin in cognitive involvement. Arch Gerontol Geriatr. 2004, 9(Suppl):13-2.

3. Dix R, Hallpike CS: The pathology, symptomatology and diagnosis of certain, common disorders of vestibular system. Ann Otol Laryngol 1952, 6:987-1016.

4. McClure JA, Parnes LS: A cure for benign positional vertigo. Baillieres Clin Neurol 1994, 3:537-545.

doi:10.1186/1471-2318-10-S1-A100

Cite this article as: Chiarella and Cassandro: Balance in elderly: overview and personal experience in Paroxysmal Positional Vertigo (PPV). BMC Geriatrics 2010 10(Suppl 1):A100. 